\title{
LOS DERECHOS HUMANOS
}

Sumario: 1. Doble actualidad de este tema. 2. Sentido de la expresión "derechos humanos". 3. La dignidad del individuo humano. 4. Justificación filosófica del humanismo. 5. Indole de los derechos humanos. 6. Clasificación de los derechos humanos. 7. Esbozo histórico. 8. Dimensión iusnaturalista de la Declaración Universal de Derechos Humanos.

\section{Doble actualidad de este tema}

El tema de los llamados "derechos humanos" tiene una doble actualidad: teórica y práctica. Teórica, porque la mayoría de la filosofía del derecho de nuestro tiempo desenvuelve reciamente una estimativa jurídica, las más de las veces con signo iusnaturalista. Actualidad práctica, porque seguramente en ninguna otra época de la historia se habla tanto de los derechos humanos como en la presente. Este es un tema al que alude con enorme frecuencia el hombre de la calle y sobre el cual se publican noticias, manifiestos, de modo que está presente en la prensa diaria y periódica. No sería exagerado decir que las tres cuartas partes de la producción filosófico-jurídica de los últimos tres decenios se ha desarrollado como un renacimiento del derecho natural. Claro está que no por las vias de la llamada Escuela Clásica Moderna Racionalista del Derecho Natural, representada por Grocio, Althusio, Thomasio, Pufendorf, Heineccio, etc. Porque dicha escuela contribuyó a desacreditar el derecho natural. La mayor parte de las críticas dirigidas en contra del iusnaturalismo apunta a los desvaríos frenéticos de esa escuela, cuyas exageraciones llevaron al ridículo al derecho natural. El renacimiento muy fecundo y frondoso del iusnaturalismo en nuestros días está radicalmente alejado de esa escuela. Tiene ese renacimiento iusnaturalista algunos contactos muy importantes con el llamado derecho natural clásico de inspiración estoica, aristotélica y cristiana; y, por otra parte, tenemos la floración de un nuevo derecho natural de inspiración existencial; y muchos autores sueltos con obra original sobre este tema.

Entre los iusnaturalistas que han renovado el derecho natural llamado clásico de inspiración estoica, aristotélica y tomista en los paises de lengua alemana, se debe mencionar, entre otros, a los siguientes: Emil Brunner, Johannes Messner, Alfred Verdross. En lengua francesa, Georges Renard, Léon Husson, Jacques Maritain, Jacques Leclercq, Michel Villey. En los paises de lengua castellana: Joaquín Ruiz-Giménez Cortés, Agustín de Asís, Antonio Truyol, Eustaquio Galán Gutiérrez, José Corts Grau, Antonio Fernández Galiano, Emilio Serrano Villafañe, en España. Y Rafael Preciado Hernández, Abel Naranjo Villegas, Manuel Río, Alfredo Fraguerio, Octavio N. Derisi, Héctor González Uribe, Antonio Gómez Robledo, en Iberoamérica. En los 
Estados Unidos de Norteamérica: John Wu, Brandis P. Lebuffe, James Hayes, Georg Constable, Harold Mckinnon, Anton Hermann Chroust.1

Con alguna raíz existencial deben ser citados Karl Jaspers, Hans Welzel, Erich Fechner, Werner Maihoffer, Agustín Basave Fernández del Valle. ${ }^{2}$

Entre los axiólogos del derecho con tendencia iusnaturalista y con matices originales hay que mencionar a los siguientes: Helmut Coing, Edgar Bodenheimer, Arnold Brecht, Passarin D'Entreves, Lon Fuller, Edmond Cahn Del Vecchio, Bartolomés, Luis Legaz Lacambra, Antonio Enrique Pérez Luño, Cayetano Betancur, Eduardo García Máynez y yo mismo. ${ }^{3}$

\section{Sentido de la expresión "derechos humanos"}

Conviene recordar el papel de largo alcance desempeñado por la doctrina de los derechos naturales del hombre o derechos humanos básicos en la elaboración de la parte dogmática de casi todas las constituciones del siglo xIx en los países de cultura occidental.

Fue decisiva y arrolladora la influencia ejercida por las declaraciones de derechos del hombre de las otrora colonias inglesas independizadas y que formaron los Estados Unidos de Norteamérica. ${ }^{4}$ Esos textos, inspirados en el pensamiento de la Ilustración europea, sirvieron en gran parte de modelos para las dos declaraciones francesas de los derechos del hombre y del ciudadano - la de 1789 y $1793 .{ }^{5} \mathrm{Y}$ todas esas declaraciones inspiraron a la mayor parte de constituciones políticas elaboradas en el siglo xIx.

Por otra parte, hay que reconocer que la doctrina de los derechos naturales o básicos del hombre no tuvo mucho prestigio en la teoría jurídica de la segunda mitad del siglo xIx. A esto contribuyó en gran manera la influencia del positivismo. Se razonaba de este modo: no se puede hablar de derechos naturales o básicos con independencia del derecho positivo y qué no estén sancionados por el Estado. Se quería interpretar las palabras "derechos del hombre" como una especie del concepto que del derecho subjetivo da la teoría general o fundamentảl de lo jurídico, y partiendo de esa interpretación tenían toda la razón las objeciones formuladas contra la doctrina de los derechos humanos básicos.

Pero es que el sentido en el cual se había hablado y se sigue hoy ha-

1 Para exposiciones y bibliografía de estos autores, véase Luis Recaséns Siches, Panorama del pensamiento juridico en el siglo XX, dos tomos, Ed. Porrúa, México, 1963.

2 Ibid.

3 Ibid.

4 Véase: Georg Jellinek, Die Erklärung der Menschen-und Bürgerrechten, Zweite Auflage, Leipzig, 1904.

5 Véase Boutmy, "La Déclaration des Droits de l'Homme et du Citoyen et M. Jellinek", en Annales des Sciences Politiques, XVII Année, París, 1902; Giorgio del Vecchio, Los derechos del hombre y el Contrato Social, trad. de Mariano Castaño, Instituto Editorial Reus, Madrid, s. f. 
blando de los derechos fundamentales del ser humano es por completo distinto. En este contexto "derecho" en la frase "derechos del hombre" no significa lo mismo que la noción que del "dereceho subjetivo" da la teoría juridica fundamental. Significa otra cosa: significa un conjunto de principios axiológicos fundamentales que deben ser obedecidos por el legislador, de modo especial por el legislador constituyente. Significa una serie de valores ideales que deben ser encarnados en el Derecho positivo. ${ }^{6}$

Adviértase, por otra parte, que la discusión en este asunto tenia mucho de bizantina. Porque la casi totalidad de las constituciones de los Estados civilizados, notoriamente de los pertenecientes al círculo de cultura occidental, transcribían ya en términos de derecho positivo aquellos principios ideales. Y después de la segunda Guerra Mundial y de la proclamación de la Declaración Universal de Derechos Humanos hecha por la Asamblea General de las Naciones Unidas el 10 de diciembre de 1948 en París, la casi totalidad de las nuevas constituciones convierte en derecho positivo los principios expresados en dicha Declaración.

En nuestros días, habitualmente las conversaciones, los debates, las protestas, en relación con los derechos humanos no se refieren a la necesidad de formularlos en las constituciones, pues esto se ha llevado ya a cabo. Se refieren a otra cosa: al incumplimiento por parte de muchos gobiernos de aquello que figura proclamado no ya sólo en tratados de filosofía del derecho y en la Declaración Universal, sino en el derecho positivo. Casi siempre cuando hoy se habla de violación de los derechos humanos estamos en presencia no sólo de un desvío del derecho positivo frente a la axiología jurídica, antes bien de un incumplimiento de textos de derecho constitucional positivo.

Claro que la circunstancia de que los principales derechos básicos del ser humano están reconocidos en los textos constitucionales de casi todos los paises dota a esos derechos de un carácter especialmente solemne y fundamental enraizado en una concepción humanista del mundo y de la vida. $Y$, asf, la expresión "derechos del hombre" o "derechos humanos" tiene siempre un doble significado: no sólo la alusión a determinados textos de derecho constitucional positivo, sino también a los principios ideales de axiologia jurídica.

El hecho de que precisamente en nuestro tiempo se hable y se discuta sobre los derechos humanos se debe a una trágica paradoja: a la circunstancia de que las violaciones de tales derechos tienen hoy en día por desgracia dimensión masiva. Y una vez más se verifica el dicho de que la validez ideal de una norma resplandece tanto más cuanto que sea desconocida en la realidad.

- Véase Luis Recaséns Siches, Tratado general de filosofia del derecho, $3^{\mathrm{a}}$ ed., Edit. Porrúa, 1965, pp. $55^{1}$ ss. 


\section{La dignidad del individuo humano}

Todos los derechos humanos radican en el principio de la dignidad del hombre. Tal vez una de las mejores formulaciones de este principio sea la dada por Kant: consiste la dignidad en que el individuo humano es un sujeto con fines propios, es un autofín y que, por consiguiente, no debe jamás ser degradado a la situación de mero medio para el cumplimiento de finalidades ajenas.

En la filosofía griega de la antigüedad clásica (Platón y Aristóteles) encontramos la idea de la dignidad humana, aunque frustrada en cuando a sus consecuencias de libertad para todos los seres humanos. ${ }^{7}$ El hecho de que esas filosofías subrayaron la primacía de la razón abría un camino para una ética humanista, si bien no tuvieron éxito en cuanto a las consecuencias de dicha dirección ética cuando desarrollaron la filosofía moral y la filosofía jurídica. Aquel camino, que invita a llegar a la idea de la dignidad, consistía en reconocer que el hombre no es una cosa sometida a la ciega causalidad, a meros fines y poderes extraños. Por el contrario, gracias a su razón, el hombre puede alcanzar la meta de una vida buena. Cierto que el hombre puede degradarse a sí mismo sometiéndose a pasiones meramente animales y subordinándose a la materia. Sin embargo, puede también vivir de una manera divina, en tanto en cuanto satisfaga los requerimientos de su alma y actúe de acuerdo con su razón. La carreta de su alma es conducida por todas las fuerzas de su naturaleza. Sin embargo, el hombre puede triunfar, en la medida en que es capaz de elevarse a si mismo y de someter a las fuerzas bestiales. Gracias a su mente racional, el hombre es capaz de alcanzar el conocimiento de las más altas verdades y finalidades. Esto concede al hombre su dignidad propia y lo hace superior a todos los otros seres vivientes de la tierra.

A pesar de esas luminosas ideas, que invitan al reconocimiento de la dignidad humana, Platón y Aristóteles no llegaron a formular este principio con una dimensión universal y admitieron la esclavitud, so pretexto de que los esclavos no participan en la razón; y discriminaron contra las mujeres y los niños porque decian que su participación en la razón era menor que la de los varones adultos.

En la antigüedad clásica, sólo los filósofos estoicos, especialmente los latinos -Epicteto, Séneca y Marco Aurelio- sostuvieron una concepción universal de la humanidad, y una igualdad de todos los seres humanos en cuanto a la dignidad que pertenece a cada uno de ellos.

El pensamiento de la edad moderna contribuyó en gran medida a vigorizar la idea de la dignidad, en tanto en cuanto sostuvo que el hombre es

I Véase la antología de Julián Marías, El tema del hombre, Revista de Occidente, Madrid, 1943; Russell W. Davenport, The Dignity of Man, Harper, Nueva York, 1955. 
el centro y la meta de toda la cultura. A la mencionada formulación dada por Kant, éste añadió lo siguiente: todas las cosas en este mundo tienen un precio - es decir un valor relativo o instrumental-, excepto el hombre, quien no tiene precio, porque tiene dignidad, porque es un fin en si mismo y para sí mismo.

Max Scheler ${ }^{8}$ y Nicolai Hartmann ${ }^{9}$ fundamentaron la idea de la dignidad humana sobre la base de su teoría de los valores morales: los más altos y que se cumplen en la persona humana y por virtud de la libre decisión de ésta.

Por mi parte yo he contribuido al mismo propósito mediante la justificación filosófica del humanismo.

De acuerdo con la concepción humanista, el Estado y todas las instituciones tienen sentido y justificación como un medio puesto al servicio de las personas individuales, como un instrumento para la realización de los fines de éstas. Esto puede expresarse parafraseando unas palabras bíblicas relativas al sábado (es decir, a las instituciones): el Estado fue hecho para el servicio del hombre y no viceversa.

Por el contrario el antihumanismo (por ejemplo, el totalitarismo) afirma que en el hombre se dan valores sólo en tanto en cuanto él sea una parte del Estado o un vehículo para los fines del mismo; es decir, que el hombre individual, en tanto que tal, carece de toda dignidad propia, y viene en cuestión solamente en cuanto sirve como medio para algún fin transpersonal del Estado. De acuerdo con el antihumanismo - llamado también transpersonalismo-, el hombre queda degradado a una especie de pasta al servicio de funciones supuestamente objetivas que se realicen en la gloria del Estado, en la raza, en la clase proletaria, esto es, en dimensiones transpersonales. ${ }^{10}$

\section{Justificación filosófica del humanismo}

Yo entiendo que es posible justificar el humanismo y mostrar el error absoluto del antihumanismo o transpersonalismo, mediante varios argumentos filosóficos.

Aun cuando el idealismo filosófico ha sido superado por la filosofía de la vida o existencia humana, de él queda una verdad firme, la verdad de que mi conciencia constituye el centro, el soporte, y la prueba de todas las demás realidades. La conciencia inevitable y necesariamente es el centro del universo, de mi universo, que es el único mundo al cual puedo referirme con autenticidad de experiencia inmediata. Yo no soy una de tantas cosas que

8 Véase Max Scheler, Der Formalismus in der Ethik und die materiale Wertethik, Zweite Auflage, 1922.

9 Véase Nicolai Hartmann, Ethik, 1926, pp. 159 ss.

10 Véase Luis Recaséns Siches, Tratado general de filosofía del derecho, $3^{\text {a }}$ ed., Edit. Porrúa, México, 1965, cap. 19. 
en el mundo hay, pues yo en todo caso soy el testigo de todo lo demás. La perspectiva creada por la individualidad es ineludible y necesaria: constituye uno de los componentes de la realidad.

El universo es mi universo. El mundo aparece como el correlato del yo, como mi mundo, y si yo desaparezco, conmigo desaparece también mi mundo. Se dirá quizá que el mundo continuará existiendo para las demás gentes después de que yo haya desaparecido. Esto es correcto. Pero sucede que esta afirmación correcta, es una teoría correcta elaborada en mi vida, $y$, consiguientemente una parte de mi mundo.

La vida humana, la vida individual, mi vida, constituye la realidad primaria y básica; y consiste en la correlación entre el yo y su mundo. Vivir es estar ocupado con un mundo en el cual yo me encuentro a mí mismo necesariamente. Mejor dicho nos encontramos mutuamente, unidos de un modo necesario, en una compañía inexorable. Por lo tanto, mi vida requiere dos ingredientes esenciales: el mundo y yo, yo y el mundo.

Los objetos del mundo, al igual que yo mismo, se presentan sólo en la realidad de mi vida, que es la realidad indubitable, la cual además es la realidad fundamental que sostiene y condiciona todas las demás realidades.

Ahora bien, si todo lo que hay tiene expresión tan sólo en mi vida, la cual es la vida individual; si todas las otras cosas dependen de mí -aunque es también cierto que yo dependo de ellas_; si todas las otras cosas aparecen sólo en la realidad de mi vida, entonces es evidente que en una concepción del mundo la primacía le corresponde a mi vida, que es una vida individual.

La llamada cultura -religión, filosofía, ciencia, arte, moral, derecho, Estado, tecnología, economía, etc.-, es un conjunto de cosas y de obras que el hombre hace en su vida; y consecuentemente tienen sentido y justificación sólo en su vida y para su vida.

La cultura está constituida por acciones y obras humanas que aspiran a realizar ideas de valor; está integrada por acciones y productos, los cuales intentan encarnar la verdad, en el conocimiento científico y filosófico del universo; dar forma sensible a la belleza en el arte; conseguir la justicia en la sociedad, mediante el derecho; utilizar la naturaleza y superar sus resistencias, gracias a la tecnología; etc. Entonces, la cultura, como una intención de aproximarse a los valores de verdad, bondad, justicia, belleza, utilidad, poder, etc., tiene sentido sólo para el hombre, quien no posee tales valores en plena medida y quien, sin embargo, experimenta la necesidad de esforzarse en la conquista de los mismos. Por consiguiente, la cultura no tiene sentido para la naturaleza inconsciente ni para los animales, ni lo tiene tampoco para Dios, quien por esencia es absoluta verdad, bien total, justicia suprema, belleza completa, poder infinito. ¿Qué necesidad tiene Dios de la ciencia, si lo conoce todo en eterna actualidad? ¿Qué necesidad tiene de la moral si Él es el bien supremo? ¿Qué necesidad tiene del derecho si Él es justicia 
perfecta? ¿Qué necesidad tiene del arte si Él es completa belleza? ¿Qué necesidad tiene de la tecnología si El es omnipotente? Ahora bien, por otra parte, la cultura aparece llena de sentido para nosotros los humanos, en tanto que la concebimos como una función y obra nuestra. Porque el hombre no sabe, pero necesita saber, por esa razón elabora ciencia. Porque el hombre, que no alberga en sí la belleza pura, pero no obstante desea relacionarse con ella, por eso crea el arte. Porque el hombre es pecador pero siente la necesidad de redimirse, por esta razón tenemos la ética y la religión. Porque la sociedad debe ser organizada de acuerdo con la justicia, por eso elaboramos derecho. Porque el hombre es desvalido, pero siente la necesidad de aprovechar y dominar los elementos de la naturaleza, por esta razón produce tecnología. Así pues, consiguientemente, el hombre es de modo necesario el centro nato de toda cultura y su punto de gravitación final. $Y$ puesto que los supremos valores que pueden ser referidos al hombre son los éticos, por eso la idea de la dignidad personal debe regir siempre por encima de todas sus otras tareas. Si la vida humana, la vida individual, la de cada uno, es la realidad básica, si los valores, aunque objetivos, se presentan en nuestra vida ni más ni menos como todo lo demás que en el universo hay, y por eso tienen una dimensión intravital; si el agente de realización de los valores es el hombre, el único capaz de entenderlos, de seguir su llamada, de esto se deduce que la realización de los valores tiene sentido sólo para los humanos. Las cosas en las cuales residen valores -entre ellas, la sociedad, que es un mecanismo, un instrumento-, constituyen bienes, sólo en la medida en que representan un instrumento de servicio para el hombre, en la medida en que son condiciones para que su conciencia encarne los supremos valores, que son los destinados al individuo como tal.

Subrayo que no niego ni desconozco que en la colectividad pueden y deben encarnar valores; pero esos valores, propios de la colectividad, son valores en tanto en cuanto constituyen instrumentos o condiciones para la realización de los valores propios del individuo.

El gran error cometido por el antihumanismo o transpersonalismo es el siguiente: no toma en cuenta que la colectividad no tiene una realidad substante, deja de ver que la colectividad no tiene un ser en sf mismo, independiente del ser de los individuos que la componen. Por otra parte, el ser de los individuos consiste en un ser para sí mismos, en un ser autónomo e independiente. Por esta razón la colectividad debe respetar al individuo en su modo de ser peculiar, en los valores que le están destinados, y debe reconocer su autonomia.

El individuo no es simple y puramente una parte del todo. Aunque el individuo desde luego tiene que ser un miembro de la sociedad, es al mismo tiempo superior a ésta. Es superior a la colectividad, porque es persona en el más pleno y auténtico sentido de esta idea, lo cual la sociedad no podrá 
serlo jamás. La colectividad carecería de sentido, si no se afirmase como un medio para los individuos.

Esto no debe ser malinterpretado en el sentido - que sería un gran error- de que se niegue que en la colectividad puedan y deban encarnar valores; ni tampoco en el sentido -que sería también una gran equivocación- de que la sociedad sea considerada como algo puramente eventual. El individuo es esencialmente social, tanto, que un individuo aislado no puede tener realidad, porque resultaría imposible. Un individuo aislado es una pura abstracción que no se puede dar en la realidad. El individuo existe sólo en sociedad; vive sobre el nivel histórico de ésta, apoyándose en ella y haciendo uso de los bienes que encuentra en la misma. Tanto el anacoreta como Robinson llevan la colectividad dentro de sí mismos y viven sobre el nivel que ésta les proporciona. El individuo se apoya sobre los valores realizados a través de la historia y trasmitidos a él por la colectividad; y casi todo lo que hace descansa sobre esos bienes comunales; aunque en varios casos logra elevarse por encima del nivel histórico de esos bienes que la colectividad le ha trasmitido.

Pero aunque lo social es esencial al hombre, los bienes realizados en la colectividad son bienes que tienen un carácter instrumental; son medios para la realización de valores más altos, los cuales pertenecen sólo al individuo y tienen que ser cumplidos y disfrutados sólo por el individuo. Desde luego, sin sociedad no existe el hombre. Pero el hombre -aquí se entiende el hombre individual, que es el único que constituye una realidad básica y substante- es axiológicamente superior a la sociedad. Porque la sociedad es algo hecho por él y para él. El hombre tiene conciencia, lo que la sociedad no puede nunca tener.

\section{Indole de los derechos humanos}

Los derechos humanos son principios o máximas de estimativa jurídica, que se expresan como criterios supremos que deben ser obedecidos y desenvueltos prácticamente en la elaboración del derecho positivo, tanto por el legislador como por los órganos jurisdiccionales. Con estas palabras se trata de indicar que la validez intrínseca de esos principios no depenede de ningún accidente histórico, no depende de la voluntad o del reconocimiento de los hombres. Por el contrario, tales principios tienen una validez en sí y por si, porque constituyen la proyección sobre el mundo del derecho, de la esencia misma de lo humano; porque constituyen las supremas máximas implicadas por la idea de justicia; porque tienen un carácter ético necesario y universal. Además, se piensa en esos principios como la piedra de toque fundamental para determinar si un cierto orden jurídico positivo puede considerarse como justificado o no: si el régimen de un país reconoce como valo- 
res supremos los enunciados en las máximas de los derechos básicos del hombre, entonces, en conjunto, podemos considerar dicho régimen como justificado, como civilizado, como digno de que se le preste obediencia. Si, por el contrario, tropezamos con un régimen que no se inspira en el reconocimiento de la dignidad ética del individuo humano, y no la toma como el más alto de todos los valores que deben inspirar al derecho, con un régimen que niega la libertad de conciencia, de pensamiento, que no respeta la inviolabilidad del domicilio, que no admite la autonomía personal para decidir sobre el propio estado civil o sobre la libre elección de oficio o profesión, o que admite la esclavitud o el trabajo forzado impuesto unilateralmente por la autoridad, entonces se debe entender que tal régimen es monstruoso, radicalmente antihumano, e indigno de que se le preste acatamiento.

En todo caso, al emplear la expresión "derechos humanos" o "derechos del hombre" se piensa en algo que está ligado necesaria y universalmente a la esencia del ser humano, en algo que no debe ser considerado como contingente, ni como pasajero, ni como accidental. Tal vez con el cambio de las circunstancias históricas, resulte que los medios juridicos de protección, las estructuras institucionales para amparar y hacer efectivos los derechos humanos, deban experimentar transformaciones. Ahora bien, en este caso, se tratará de nuevos medios o instrumentos encaminados al mismo fin, a saber, encaminados a la protección y a la garantía de los valores humanos esenciales y de más alto rango.

Esto no significa, sin embargo, que ni siquiera en los siglos xvir y xvin, y todavía menos en el siglo xix y en el presente, haya un acuerdo exactamente unánime sobre los fundamentos filosóficos de los derechos humanos. Pero sucede que, aparte de las divergencias filosóficas sobre los supuestos y sobre las bases de esos derechos del hombre, se produce una concordancia en el terreno práctico, en cuanto a la definición de cuáles debieran ser considerados como tales derechos humanos y sobre el alcance de cada uno de ellos.

Al iniciar este artículo me he referido a diversas direcciones iusnaturalistas en el presente. La variedad vale también para el pretérito. El derecho natural fue definido y expuesto de modos muy diferentes por Tomás de Aquino, Francisco Suárez, Locke, Tomasio, Rousseau y Kant. Pero entre todas esas concepciones, y otras más, del pasado, y las direcciones del presente hay como común denominador la afirmación de que se deben reconocer unos derechos esenciales al hombre. Esta idea fue inscrita en las constituciones de los siglos XviII, xIx y xx, no porque los hombres se hubiesen puesto de acuerdo en el plano filosófico, antes bien, porque el acuerdo se produjo a pesar de las divergencias filosóficas en cuanto al fundamento de los derechos humanos. Dejando a un lado las diferencias en cuanto a las respectivas paternidades filosóficas, resulta que hay un común denominador en todo el pensamiento iusnaturalista. Este denominador común consiste en establecer una distinción 
entre ciertos derechos esenciales e inalienables que se entiende deben quedar exentos del arbitrio gubernamental, por una parte, $y$, por otra, ciertos derechos alienables cuyo establecimiento queda delegado a las comunidades y autoridades políticas, al legislador o a los jueces y que encuentran su contrapartida en el ejercicio justo y eficaz del poder. El empleo de esta diferencia se convirtió en algo tan tradicional, que se la acepta como inevitable. Cuando empezó el proceso de elaboración de la Declaración Universal de Derechos Humanos, varios de los representantes que formaban parte de la comisión constituida para tal fin, manifestaron discretamente que un texto de esta clase, que aspira a ser universal, no podía especificar una determinada filosofía. Según había recomendado ya Jacques Maritain, era posible hacer a un lado la fundamentación filosófica y buscar las coincidencias en las conclusiones prácticas. Este criterio fue aceptado por todos los miembros de la comisión. $Y$, sin embargo, a pesar de aquel acuerdo, el resultado final fue una Declaración de espíritu iusnaturalista, como lo muestran muchas de las frases insertas en dicha Declaración. Seguramente esto era inevitable, pues el mero hecho de ponerse a elaborar una declaración de derechos humanos implica que se cree que, por encima de las determinaciones del derecho positivo, por encima de lo que los Estados decidan, hay normas superiores a las que los poderes legislativos deben obedecer.

\section{Clasificación de los derechos humanos}

A la altura de nuestro tiempo podemos clasificar los derechos humanos en tres grandes grupos: $A$ ) libertades individuales; $B$ ) derechos democráticos; y $C$ ) derechos sociales, económicos y educativos.

Dentro del primer grupo (libertades individuales) se catalogan por lo menos los siguientes derechos: a la vida y a la seguridad de la persona; a la autonomía personal; a la igualdad ante la ley y a la igual protección de la ley sin distinción ninguna; a las garantías procesales; a la libertad de pensamiento, de conciencia y de religión; a la libertad de opinión y de expresión; a la libre circulación y elección de residencia; a la elección de estado civil; a la propiedad, individual y colectivamente; a la libertad de reunión y de asociación pacíficas; etc.

Al segundo grupo, es decir, a los derechos democráticos, pertenecen: el derecho a una nacionalidad; el derecho a participar en el gobierno del propio país; el derecho de acceso, en condiciones de igualdad, a las funciones públicas del propio país; el derecho de reunión y asociación políticas; el derecho de expresión; política; etc.

Al tercer grupo, el de los derechos económicos, sociales y culturales, pertenecen el derecho al trabajo, a la libre elección de trabajo, a condiciones equitativas y satisfactorias de trabajo y a la protección contra el desempleo; 
el derecho a un igual salario por trabajo igual; el derecho a una remuneración equitativa y satisfactoria que asegure al trabajador, así como a su familia, una existencia conforme al decoro humano; el derecho al descanso y a una limitación razonable de la duración del trabajo; a un nivel de vida adecuado que asegure al trabajador, así como a su familia, la salud y el bienestar, y en especial la alimentación, el vestido, la vivienda, la asistencia médica y los seguros sociales necesarios (para el desempleo, enfermedad, invalidez, viudez, vejez u otros casos de pérdida de los medios de subsistencia por circunstancias ajenas a la voluntad); a la educación; el derecho a participar libremente en la vida cultural de la comunidad, y el derecho a la propiedad intelectual o derechos de autor.

Cabría clasificar los derechos humanos desde otro punto de vista, a saber, desde el punto de vista de en qué medida necesiten de una menor o mayor regulación por el derecho positivo. Así, por ejemplo, entre los derechos humanos hay uno de carácter absoluto: la libertad de pensamiento, de conciencia y de opinión, porque consiste en la prohibición total de cualquier injerencia ajena o de las autoridades públicas, y cuya materia es que nadie sufra discriminación adversa de cualquier clase por el hecho de su pensamiento, de sus creencias y opiniones. El derecho de expresión puede ya necesitar alguna regulación por el derecho positivo, exceptuando de aquél la injuria, la calumnia y la incitación a actos delictivos.

El derecho de libre reunión y de libre manifestación puede requerir un permiso de la autoridad gubernativa por razones de orden público y de mutuo respeto. Imaginemos que dos partidos políticos radicalmente opuestos entre sí pretenden realizar una manifestación en el mismo día a la misma hora y por las mismas calles. Por razón de la paz y orden públicos, la autoridad podrá prohibir esas manifestaciones, sin perjuicio de dejar abierto el cauce para que se produzcan otras manifestaciones que no lleven inherente tal peligro.

Los derechos democráticos, principalmente el de sufragio, requieren toda una legislación especial sobre la materia, por ejemplo, la legislación electoral.

Muchos de los derechos sociales y económicos se especifican en la legislación laboral; otros, sobre todo los que se materializan en seguros sociales, requieren prestaciones positivas por parte del Estado $\boldsymbol{u}$ otros entes públicos. Esto mismo puede decirse en parte de los derechos educativos, en la medida en que el Estado u otros entes públicos estén obligados a prestar tal servicio.

\section{Esbozo histórico}

Las preocupaciones que suscitaron las declaraciones clásicas de derechos del hombre y del ciudadano eran las de evitar las arbitrariedades e injusticias cometidas por los gobernantes; las de defender a los individuos y a la sociedad contra las arbitrariedades del poder; las de asegurar para cada uno 
la esfera de la autonomía personal, y la participación activa en el gobierno de su país. Preocupaciones sin duda justificadas, que habian sido producidas por las amargas experiencias de regímenes despóticos. En cambio, los autores de aquellas declaraciones no se fijaron en otra clase de injusticias: en la explotación de unos individuos por otros individuos o por grupos social y económicamente más poderosos. Olvidaron que, si bien la dignidad de la persona individual y sus libertades son los valores más altos, sucede que tales principios no pueden conseguir auténtica efectividad, cuando falta el minimum indispensable de medios materiales para satisfacer las urgencias perentorias de la vida, de la vida biológica: alimentación suficiente para uno mismo y su familia, morada decorosa, aseguramiento frente a eventualidades desventuradas (accidentes, desempleo, invalidez, etc.). Olvidaron que la igualdad formal ante la ley, aunque constituya un imperativo de alto rango y de largo alcance, en la práctica significa muy poco en los casos en que de hecho existen desigualdades sociales y económicas tan desproporcionadas que entregan unos individuos que gimen en la miseria al arbitrio de otros que se prevalecen de su opulencia. Olvidaron que la libertad de contratación y la igualdad formal entre las partes contratantes adquiere de hecho significaciones no sólo diferentes, sino opuestas cuando resulta que, en fin de cuentas, esa libertad representaba para el empresario la libertad de elegir entre seguir haciéndose más rico o renuncia a ulteriores incrementos de su fortuna, mientras que para el trabajador significaba la opción entre morirse de hambre o aceptar las condiciones laborales que unilateralmente le ofrecía el patrono, condiciones muchas veces ominosas. Olvidaron que la igualdad formal ante la ley, constituyendo como sin duda constituye un principio básico inderogable, es insuficiente si no se establece un mínimo de igualdad de oportunidades, para lo cual se debe proporcionar formación educativa a todos, con objeto de ponerlos en condiciones de aproximarse de facto a aquel ideal; y conceder además las facilidades de crédito necesarias para determinados trabajos y ocupaciones.

Es exigencia de justicia esforzarse por liberar a los seres humanos frente a la angustia de la miseria, asf como frente a la total inseguridad en caso de sucesos adversos, algunos de éstos normales, como la vejez; otros, eventuales como los accidentes, la invalidez prematura, etc. Es necesario librarlos de la opresión de la miseria y de la total inseguridad, no sólo por mandato de justicia, sino además para conseguir la efectiva realización de las libertades individuales básicas, para hacer posible el desarrollo de la vida a un nivel auténticamente humano, mediante la participación en los bienes de la cultura.

La miseria es una realidad de inmenso calibre. Calcúlase que más de las dos terceras partes de los seres humanos que habitan hoy la tierra no tienen lo suficiente que comer para satisfacer decorosamente la necesidad 
de alimentación. Esto constituye una especie de caos social en el que apenas puede existir la libertad individual de un enorme número de personas. Aunque en cuanto a medidas constitucionales y legislativas se han realizado y siguen realizándose grandes progresos, precisamente mediante el reconocimiento y la puesta en práctica de los llamados "derechos económicos, sociales y educativos", el problema se complica más y más, por causa de la situación de subdesarrollo económico y social de la mayoría de la humanidad; y también por causa de una serie de factores materiales. En vastas extensiones de la superficie de la tierra, la erosión del suelo disminuye rápidamente la fertilidad de éste. Muchas zonas superindustrializadas sufren la disminución de recursos minerales. $Y$, entre tanto, la población del globo va aumentando a un tempo cada vez más veloz.

Posiblemente estos factores materiales y técnicos de índole adversa puedan quedar descartados, incluso suprimidos, en un futuro, gracias a nuevos prodigios de nuevas técnicas. Algunos sociólogos muy responsables, como, por ejemplo, Jerome Frank, anunciaron para un futuro próximo una sociedad con ocio, en la cual la jornada de trabajo no excedería dos o tres horas. Posiblemente nuevas maravillas técnicas puedan afrontar ventajosamente las dificultades de hoy. Pero hoy por hoy, aún no disfrutamos de esos remedios que tanto alivio podrían traer; y tenemos todavía que encararnos con el hecho de una ingente miseria y de dificultades materiales muy graves.

En el campo de las realizaciones constitucionales debemos sentirnos orgullosos por el hecho de que México, con su Constitución de 1917, fue quien inició en la historia presente del mundo la formulación constitucional de los derechos básicos de carácter social, económico y educativo. A partir de esa fecha, la mayor parte de las constituciones que fueron proclamadas en varios países del mundo incluyeron una lista de derechos básicos de tal índole. Recordemos de modo especial la Constitución de Weimar de la República alemana, de 1919 .

Tales realizaciones constitucionales fueron precedidas y fomentadas por un largo desenvolvimiento de nuevas ideas en materia de axiología social, jurídica y política, desde el siglo xix y en los tres primeros lustros del xx. El contenido de esos derechos sociales, económicos y educativos se presentó en el siglo xIx en una serie de reivindicaciones propugnadas en programas e idearios socialistas en la Gran Bretaña, Francia y Alemania. También en otros países, que más o menos tomaron inspiración de aquéllos. Esos movimientos sociales constituyeron el impulso de enorme alcance y con progresiva eficacia para colocar en el primer plano de la atención pública la urgencia de atender a tales derechos sociales y económicos. Sucedió, empero, que esas ideas que al principio aparecieron como formuladas y defendidas por los socialistas, poco a poco, al correr del tiempo, fueron siendo aceptadas por pensadores, por políticos y estadistas que no pertenecian al socialismo; $y$ 
fueron incorporándose a casi todos los programas políticos, incluso a los de partidos conservadores, hasta el punto de que hoy en día constituyen tal vez uno de los denominadores comunes de mayor extensión en el mundo, por lo menos en lo que se refiere a programación, si bien mucho menos en lo que atañe a realidades eficaces.

Pero es justo reconocer que, en el plano de las ideas e incluso de los textos jurídicos, los principios sobre los derechos sociales, económicos y educativos tienen una prosapia anterior, y por cierto muy ilustre. La tienen nada menos que en algunas importantes ideas de los enciclopedistas franceses, y en algunos textos de la segunda Declaración Francesa de derechos del hombre y del ciudadano (1793). En esta declaración leemos: "los socorros públicos son una deuda sagrada. La sociedad debe la subsistencia a los ciudadanos desventurados, sea proporcionándoles trabajo, sea asegurando los medios de subsistencia a quienes carecen de la posibilidad de trabajar" (artículo 21). "Todo hombre puede comprometer sus servicios, su tiempo; pero no puede venderse ni ser vendido. Su persona no es una propiedad alienable. La ley no reconoce la domesticidad. Tan sólo puede existir un contrato de servicios y de reconocimiento entre el hombre que trabaja y el hombre que lo emplea" (art. 18). "La instrucción es necesidad de todos. La sociedad debe favorecer con todo su poder los progresos de la razón pública y poner la instrucción al alcance de todos los ciudadanos" (art. 22). "La garantía social consiste en la acción de todos para asegurar a cada uno el disfrute y la conservación de sus derechos" (art. 23). ${ }^{11}$

Los autores de esos artículos fueron nada menos que Condorcet y Robespierre. $\mathrm{Y}$ estos artículos desempeñaron un considerable papel durante la época de la revolución de 1848 . Los socialistas franceses, especialmente Louis

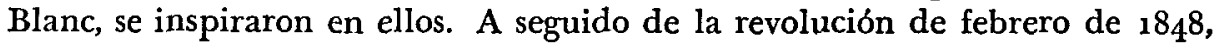
el gobierno provisional proclamó solemnemente el "derecho al trabajo"; pero después tal derecho no fue incluido en la constitución del 4 de noviembre de 1848. Con todo, en esta constitución se lee lo siguiente: "La República francesa se ha propuesto asegurar un reparto más y más equitativo de las cargas y de las ventajas de la sociedad y de aumentar el bienestar de cada uno" (art. 1). "La República debe proteger al ciudadano en su persona, su familia, su religión, su propiedad, su trabajo, y poner a la disposición de cada uno la instrucción indispensable para todos los hombres; la República debe, por medio de una asistencia fraternal, asegurar la existencia de los ciudadanos necesitados, sea procurándoles trabajo, en los límites de sus recursos, sea en defecto de éste, dando los socorros a quien no pueda trabajar" (art. 8). "La sociedad favorece y estimula el desenvolvimiento del trabajo por medio de la enseñanza primaria gratuita, la educación profesional, la

11 Véase Georges Gurvitch, La Déclaration des Droits Sociaux, Editions de la Maison Française, Nueva York, 1944, Pp. 26 ss. 
igualdad de relaciones entre el patrón y el obrero, las instituciones de previsión y de crédito, las instituciones agrícolas, las asociaciones voluntarias, y el establecimiento por el Estado, los departamentos y los municipios de obras públicas apropiadas para emplear los brazos desocupados" (art. 13). Entre los textos constitucionales del siglo $\mathrm{xx}$ anteriores a la segunda Guerra Mundial, que contengan explícita o implícitamente declaraciones de derechos sociales, económicos y culturales hay que citar: la Constitución de los Estados Unidos Mexicanos de 1917, la Constitución del Reich alemán de 1919, la Constitución de la República española de 1931 y también la Constitución de la urss de 1936 .

Entre esas constituciones, la mexicana de 1917 es la más fiel a la libertad de los individuos y de los grupos. Aunque, en tanto que mexicanos, estamos bien familiarizados con las normas de nuestra Constitución, no será ocioso recordar que, entre otros, ella proclama los siguientes derechos sociales: el derecho del obrero a que el contrato de trabajo no disminuya la libertad del hombre y no limite sus derechos políticos y civiles, el derecho a la eliminación de todos los monopolios; el derecho a la libertad sindical y el derecho de huelga; el derecho al arbitraje y a la conciliación ejercidos por órganos paritarios entre obreros y patronos; el derecho a salarios equitativos y a condiciones satisfactorias de trabajo, siendo estas últimas garantizadas por la responsabilidad de los patrones en el caso de enfermedades y accidentes profesionales; el derecho a la protección y al mantenimiento de cajas de seguros y de cooperativas de consumo y de producción; el derecho de la Nación de imponer a la propiedad privada todas las limitaciones y todas las modalidades que sean dictadas por el interés general.

Las constituciones del Reich alemán de $19^{1} 9^{12}$ y de la República española de 1931 -ésta muy influida por la primera - al formular los "derechos fundamentales aplicados a la vida económica y social" tuvieron a la vista más las prerrogativas y las funciones del Estado servidor, protector y señor que los derechos de los grupos y de los individuos. Esto es tanto más curioso cuanto que, no sin haber experimentado la influencia de la revolución rusa, estas dos constituciones introdujeron una representación obrera en las fábricas y las empresas, representación que, por otra parte, no llegó a desenvolverse de un modo suficiente. Según la Constitución alemana de Weimar: "el matrimonio está, en tanto que principio de la familia, de la conservación y del incremento de la nación, colocado bajo la protección particular de la Constitución... El Estado y los municipios deben velar por la pureza, la salud y la mejora social de la familia. Las familias numerosas tienen derecho a una ayuda que compense sus cargas. La maternidad tiene derecho a la protección y a la asistencia del Estado" (art. 119). "La educación de los hijos,

12 Véase Georges Gurvitch, op. cit., pp. 34-37. 
en vista de su desarrollo físico, intelectual y social, es el primer deber de los padres; el Estado vigilará la manera como cumplan ese deber" (art. 120). "La legislación debe asegurar a los hijos naturales, sobre su desarrollo físico, intelectual y social, las mismas condiciones que para los hijos legítimos" (art. 121). "La juventud debe ser protegida contra la explotación así como contra el abandono moral, intelectual o físico. El Estado y el municipio deben organizar las instituciones necesarias para esta finalidad" (art. 122). En cuanto a la "esfera económica": "la vida económica debe ser organizada de acuerdo con los principios de la justicia y con vista a garantizar a todos una existencia digna del hombre" (art. 151). "Se debe dar a todo alemán la posibilidad de ganar su vida por un trabajo productivo. En caso en el cual no se le pueda procurar una ocupación conveniente, se le asegurarán los medios de existencia necesarios. Los detalles están regulados por las leyes particulares del Reich" (art. 163). "El trabajo está colocado bajo la protección especial del Reich" (art. 157). "La libertad de coalición para la defensa y la mejora de las condiciones de trabajo y de la vida económica está garantizada a cada uno y a todas las profesiones" (art. 159). "El Reich organizará, con el concurso adecuado de los asegurados, un sistema de seguros para la conservación de la salud y de la capacidad de trabajo, la protección de la maternidad, y la previsión contra las consecuencias económicas de la vejez, de la invalidez y de los accidentes" (art. 161). "La legislación y la administración deben favorecer a la clase media independiente, en la agricultura, la industria y el comercio, y protegerla para que no sea aplastada por cargas ni absorbida" (art. 164). "Los obreros y empleados son llamados a colaborar con los empresarios sobre un pie de igualdad, a la fijación de los salarios y de las condiciones de trabajo, asi como al conjunto del desarrollo de las fuerzas económicas productivas. Las organizaciones patronales y obreras y los convenios que ellas concluyan quedan reconocidos juridicamente" (art. 165). "La propiedad está garantizada por la Constitución. Su contenido y sus límites están fijados por la ley. La propiedad implica obligaciones. El uso que se haga de la propiedad debe ser en el interés general" (art. 153). "El Reich puede, por medio de una ley y bajo reserva de indemnización, transferir al Estado la propiedad de las empresas privadas susceptibles de ser socializadas. Puede participar también y hacer participar a los Estados federados o a los municipios en la administración de empresas y sociedades económicas, o asegurarse de otra manera, una influencia preponderante en su administración. Además, el Reich puede, en caso de necesidad urgente, decidir por medio de una ley, la reunión en una explotación colectiva, sobre la base de la autonomía, de empresas y sociedades económicas, con vista a asegurar la colaboración de todos los factores de la producción y de hacer participar en la administración a los patronos y a los obreros... Las cooperativas de producción, de consumo y sus uniones pueden ser, a petición suya, comprendi- 
das en la explotación colectiva, teniendo en cuenta su constitución y sus caracteres particulares."

La Constitución española de $1931^{13}$ contiene una enumeración de derechos sociales concebidos de una manera análoga a los de la Constitución alemana de 1919 , y reduciéndolos a prerrogativas del Estado, protector y servidor, reservando, sin embargo, en ciertos casos una representación para las partes interesadas. "El trabajo en las diferentes formas constituye una obligación social y disfrutará de la protección de las leyes. La República asegurará a todo trabajador las condiciones necesarias para una existencia digna. Su legislación social reglamentará: los casos de seguros contra la enfermedad en el trabajo, la desocupación, la vejez, la invalidez y la muerte; el trabajo de las mujeres y de los niños y la maternidad serán especialmente protegidos; las instituciones cooperativas, las relaciones económico-jurídicas, los factores que contribuyen a la producción, la participación de los obreros en la dirección, en la administración y en los beneficios de las empresas y todo lo que concierne a la defensa de los trabajadores." "La República protegerá a los habitantes del campo y, con este fin, legislará, entre otras materias, sobre el patrimonio inembargable y exento de todos los impuestos, sobre el crédito agrícola, la indemnización por pérdida de las cosechas, las cooperativas de producción y de consumo, las cajas de previsión, los trabajos de irrigación y las vías de comunicación rurales." "Los servicios de la enseñanza constituyen una atribución esencial del Estado. La enseñanza primaria será gratuita y obligatoria. La República hará leyes destinadas a facilitar a los españoles necesitados el acceso a todos los grados de la enseñanza a fin de que ese acceso no dependa nada más que de la aptitud y de la vocación." "Los padres tienen para sus hijos nacidos fuera de matrimonio los mismos deberes que para aquellos nacidos en el seno del matrimonio. El Estado prestará asistencia a los enfermos y a los ancianos y protegerá la maternidad y la infancia, haciendo suya la Declaración de Ginebra relativa a los derechos del niño." "Toda la riqueza del país, quienquiera que sea su propietario, está subordinada a los intereses de la economía nacional. La propiedad podrá ser socializada... el Estado podrá, mediante una ley, controlar la explotación y la coordinación de industrias y empresas si la racionalización de la producción y los intereses de la economía nacional así lo exigen."

También otras varias constituciones europeas elaboradas entre 1920 y 1930, contienen enunciados de derechos sociales, con mayor o menor extensión. Por ejemplo, las constituciones de Estonia (1920), Polonia (1921), Rumania (1923), Yugoslavia (1921) y Danzig (1922).

Hay que mencionar también la Constitución de la uRss de 1936, la cual, si bien es superlativamente objetable desde el punto de vista de las libertades individuales, en cambio, por lo menos en el papel, aunque en las

13 Véase Georges Gurvitch, op. cit., pp. 37-39 
realizaciones haya estado lejísimos de cumplirse, formula una lista de derechos sociales. Con respecto a las declaraciones soviéticas, adviértase que no se trata de una defensa de los derechos de los trabajadores bajo el régimen capitalista más o menos atenuado, sino de los derechos sociales en un régimen en el cual ha quedado abolida la empresa privada. Por otra parte, adviértase también que, como los empresarios privados fueron suprimidos, el papel de empresario, por cierto omnipotente, fue asumido por el Estado; y, entonces, no se admite la posibilidad ni la licitud de que los trabajadores puedan caer en conflicto con el gobierno-empresario, puesto que se parte de la ficción de que hay una identidad entre los intereses del Estado y los intereses de los trabajadores.

Las nuevas constituciones proclamadas después de la segunda Guerra Mundial, en su mayoría, contienen amplias declaraciones de derechos humanos con una lista de los derechos sociales económicos y culturales. El 10 de diciembre de 1948 la Asamblea General de las Naciones Unidas reunida en París proclamó la Declaración Universal de Derechos Humanos. Varias constituciones elaboradas después han tomado como modelo esa Declaración Universal.

\section{Dimensión iusnaturalista de la Declaración Universal de Derechos Humanos}

A pesar del acuerdo tomado por la Comisión de Derechos Humanos de eliminar de la "Declaración Universal" toda referencia a supuestos doctrinales, resultó que el texto de ésta, tal y como fue finalmente proclamado, y, sobre todo su Preámbulo, contiene notoriamente vigorosos asertos iusnaturalistas. Seguramente esto era inevitable, a pesar de aquel acuerdo, pues el mero hecho de ponerse a elaborar una declaración de derechos del hombre implica que se cree que, por encima de las determinaciones del derecho positivo, por encima de lo que los Estados decidan, hay normas superiores a las que los poderes legislativos deben obedecer.

Se trata, en suma, de la tesis que constituye la base de las Naciones Unidas. Si bien es cierto que ni la Carta Fundacional, ni los Documentos emitidos después por las Naciones Unidas contienen la expresión de ninguna filosofía en el sentido de una determinada escuela o doctrina, es innegable que las Naciones Unidas se basan en el reconocimiento de unos valores, puesto que se les asigna el deber de velar por el mantenimiento de la paz. de la justicia, del respeto a las obligaciones que se siguen de los tratados, y de la observancia de los derechos fundamentales del hombre. $Y$, en el Preámbulo de la Carta, se menciona además la fe "en la dignidad y valor de la persona humana".

La "Declaración Universal" se expresa en los mismos términos de la 
Carta, acentuando todavía más este reconocimiento de unos principios, considerados como superiores al Derecho positivo nacional, y que se quiere convertir en normas jurídico-positivas internacionales. ${ }^{14}$

El Preámbulo de la "Declaración Universal" tiene ciertamente un sabor iusnaturalista, pues expresa que esos principios superiores consisten precisamente en el valor y dignidad de la persona humana, y en una serie de derechos fundamentales (considerando $4^{\circ}$ ). En el primer considerando se habla de "la dignidad intrínseca y de los derechos iguales e inalienables de todos los miembros de la familia humana". "Intrínseca" quiere decir aquí "esencial", pues tal vocablo castellano es traducción de la voz inglesa "inherent" la cual significa "lo que existe en algo como elemento, cualidad o atributo permanente e inseparable" (The American College Dictionary) o traducción del vocablo francés "inherente" que es definido como "aquello que por su naturaleza está unido inseparablemente a un objeto" (Nouveau Petit Larousse). Se añade, además, que los derechos fundamentales del hombre son "iguales e inalienables". La palabra "inalienable" es la que tradicionalmente se ha venido usando para subrayar el carácter superior de los primeros principios de axiología jurídica, que determinan los derechos humanos fundamentales. Se dice que estos derechos son "inalienables", en el sentido de que su validez no depende de ningún azar de la voluntad humana, ni de la propia ni de la ajena. El hombre posee tales derechos, no porque un legislador se los haya otorgado, sino sencillamente en virtud de su condición humana. Además, este párrafo, aquí comentado, dice que estos derechos son "iguales" y se refiere también a "todos los miembros de la familia humana". Lo uno y lo otro significan que el hombre posee tales derechos, no porque pertenezca a una cierta nación, ni porque sea ciudadano de un determinado Estado, sino sencillamente porque es hombre, porque pertenece a la familia humana. La extensión de estos derechos coincide con el ámbito de la humanidad entera.

Además, el mismo considerando primero dice que: "el reconocimiento de la dignidad intrínseca y de los derechos iguales e inalienables" del hombre, constituye la base de "la libertad, la justicia y la paz en el mundo". Así pues, en la "Declaración Universal", la libertad, la justicia y la paz son considerados como los valores supremos del Derecho, los cuales tienen como base la dignidad intrinseca o inherente y los derechos básicos de todos, no en un determinado lugar, sino en el mundo, es decir, se da a este aserto una dimensión de validez universal.

El considerando tercero de la "Declaración Universal" dice que es "esencial que los derechos del hombre sean protegidos por un régimen de derecho, a fin de que el hombre no se vea compelido al supremo recurso de la

14 Véase Declaración Universal de Derechos del Hombre, Departamento de Información Pública de las Naciones Unidas, Lake Success, 1949. 
rebelión contra la tiranía y la opresión". Este párrafo contiene implícitamente la distinción entre "derechos humanos fundamentales" en el sentido de los principios ideales que llevan a la proclamación de éstos, por una parte, $y$, por otra parte, el régimen de derecho positivo formalmente válido, en el cual tales derechos se hallan reconocidos y protegidos. Tan patente es esta diferenciación, que se considera que cuando el derecho positivo no protege los derechos humanos fundamentales, se convierte en "tiránico y opresor", y que entonces los hombres pueden sentirse en la necesidad de apelar al supremo recurso de la rebelión. Ahora bien, la idea del derecho de resistencia activa contra la tirania es una de las piezas esenciales de la mayor parte de las doctrinas iusnaturalistas (por ejemplo, de la escolástica y de varias de la Escuela Clásica Moderna). A mayor abundamiento, se declara en el segundo considerando que de hecho ha habido Estados que han desconocido y menospreciado los derechos humanos, lo cual ha originado "actos de barbarie ultrajante para la conciencia de la humanidad". De tales palabras se sigue que los regímenes que desconocen o menosprecian los derechos humanos son bárbaros, en el sentido de no civilizados. La expresión "conciencia de la humanidad" se refiere sin duda al hecho de que hay unos principios éticos que se reflejan en todos los hombres (en la humanidad) y que deben ser respetados y cumplidos por todos los pueblos y por todos los Estados.

En el considerando segundo se lee además que se ha proclamado como "la aspiración más elevada del hombre, el advenimiento de un mundo en que los seres humanos, liberados del temor y de la miseria, disfruten de la libertad de palabra y de la libertad de creencias". Es decir, se enumeran los cuatro derechos o libertades fundamentales proclamados por el presidente Franklin Delano Roosevelt. De este párrafo, se sigue que esos derechos fundamentales constituyen "la aspiración más elevada del hombre".

Este mismo pensamiento respiandece en la frase inicial de la "Proçlamación"o cláusula dispositiva: "La Asamblea General proclama la presente Declaración Universal de Derechos del Hombre como ideal común por el que todos los pueblos y naciones deben esforzarse, a fin de que, tanto los individuos como las instituciones, inspirándose constantemente en ella, promuevan, mediante la enseñanza y la educación, el respeto a estos derechos y libertades, y aseguren, por medidas progresivas de carácter nacional e internacional, su reconocimiento y aplicación universales y efectivos..." Nótese que no se dice, como es habitual cuando se legisla, que se establece. estatuye o dispone, sino que se dice que se "proclama", esto es, se proclama algo que tiene validez de por si. Se hace la proclamación para facilitar el reconocimiento y la aplicación de tales principios universales, que eran ya válidos antes de la proclamación.

Debo hacer una advertencia de largo alcance para el estudio de los lla- 
mados "derechos humanos" o "derechos del hombre". En esta materia tenemos que habérnoslas con principios axiológicos ideales puros, con validez necesaria, $\mathrm{y}$, además, universales. Pero tenemos que habérnoslas no solamente con esos criterios estimativos puros, sino también con la proyección de los mismos a unas determinadas realidades sociales de nuestro tiempo. Es probable que aquellos mismos criterios estimativos puros, si fuesen aplicados a otras realidades históricas muy diferentes de las de los pueblos civilizados de Occidente en nuestro tiempo, producirian consecuencias distintas de las que se configuran en las "Declaraciones de Derechos Humanos" de nuestra época y en nuestro mundo.

Hay que evitar el pensamiento de que en materia de derechos humanos todo es absoluto. Hay ciertamente una raíz axiológica absolutamente válida. Es precisamente por esta razón por la que se estudian filosoficamente los llamados derechos humanos; pero en las formulaciones que de ellos conocemos, incluso en las mejores, hay la inevitable y correcta influencia de unas determinadas realidades históricas, las de nuestro tiempo, las cuales son ingredientes empíricos, fácticos, contingentes, variados y cambiantes.

Admitir junto a las dimensiones de validez necesaria, otras dimensiones contingentes y variables en materia de derechos humanos no implica, ni remotamente, restar importancia ni alcance a los valores puros en este campo. En otras culturas, en otras condiciones, la configuración de los derechos del hombre podria presentar probablemente algunas diferencias; pero en esta materia, y sobre todo en materia de libertades individuales, esas diferencias serían relativamente pequeñas y en todo caso inesenciales.

INSTITUTO de INVESTigaciones Filosóficas

LuIS Recaséns SicHes Universidad Nactonal Autónoma de México 